\title{
Treatment Method of Water based on the Magnetic Devices
}

\author{
Nguyen Le Thai", Dang Van Hai, and Trinh Tien Tho \\ Faculty of Mechanical Engineering and Technology, Ho Chi Minh City University of Food Industry (HUFI), Ho Chi Minh City, Vietnam
}

DOI: $\underline{10.36348 / \mathrm{sijb} .2020 . \mathrm{v} 03 \mathrm{i} 07.003}$

| Received: 01.07.2020 | Accepted: 10.07.2020 | Published: 14.07 .2020

*Corresponding author: Nguyen Le Thai

\section{Abstract}

Magneto - Electric Machine, a device based on the principle of electromagnetic radiation in water is used to separate the bonds of compounds in water. Since magnetic treatment has a variety of selective influences on different substances and processes, its application has wide potentials in the practice. This paper presents a research result on the influence of the magnetic field on the water's Total Dissolved Solids (TDS) and Potential of Hydrogen (PH). Then, the experimental results are conducted to show that the fluctuation of the magnetic field affects the concentration of PH and TDS in water.

Keywords: Water Magnetic Devices.

Copyright @ 2020: This is an open-access article distributed under the terms of the Creative Commons Attribution license which permits unrestricted use, distribution, and reproduction in any medium for non-commercial use (NonCommercial, or CC-BY-NC) provided the original author and source are credited.

\section{INTRODUCTION}

Mineral fouling is a frequent technological problem during water processing. Encrustation in pipelines reduces the flow capacity, thus requiring more pumping power. When to precipitate on heated surfaces, it also reduces heat transfer due to the insulation effect of minerals. The predominant scale from ground and terrestrial waters is calcium carbonate owing to its decreasing solubility with $\mathrm{CO}_{2}$ gas released from the solution when the temperature is increased or the pressure is reduced. Its solubility also depends on the $\mathrm{pH}$; for instance, when $\mathrm{NaOH}$ is added $\mathrm{CO}_{2}$ forms additional carbonate ions and the precipitation of $\mathrm{CaCO}_{3}$ occurs. Depending on water processing conditions, $\mathrm{CaCO}_{3}$ commonly precipitates in amorphous and various crystalline modifications: rhombus-shaped calcite that may adhere into highly- compact scale; needle- like aragonite that tends to form a brittle scale, but in rigorous thermal and hydrodynamic conditions grows into a hard scale, and spherical vaterite that usually form a powder- like scale.

Economic and environmental concerns have led to the development of alternative physical means for hard- scale prevention: by the usages of permanent magnets [1- 3], electromagnetic coils [4-5], electrodes [6], and ultrasonic pretreatment [7]. The common principle of these treatments is the pre- precipitation of calcium carbonate (a homogenous nucleation/coagulation in bulk water) into fine suspended particles that later in critical regions (e.g. under the hot conditions of the heat- exchanger) offer preferable surfaces for crystallisation, depositing as a loosely adhered sludge or being carried further by the water- flow.

The anti- scale magnetic treatment of hard water has been employed for more than half a century, but the application has sometimes proved to be ineffective due to insufficient data about efficiency requirements [8] and still some influencing factors are unrecognized [9].

Here, a modelling of electromagnetic radiation for water source with concentration of PH and TDS source exceeds Vietnam standard for boilers.

\section{DEVICE CONSTRUCTION \\ Principle of creating magnetic field}

Magnetic water treatment technology is a device based on frequency modulation using a coil wound around a pipe section of the water system. This coil is triggered by a constantly changing power supply of polarity, frequency and amplitude. When water goes through the pipe section, which is rolled by this coil, they are inhibited, losing their ability to adhere to the wall of the device, and melting of older deposits, so that the surface of the device is free of scale, increasing heat transfer efficiency, saving energy, and extending the life of the heat transfer. The principle of creating a magnetic field is shown in Figure 1. 


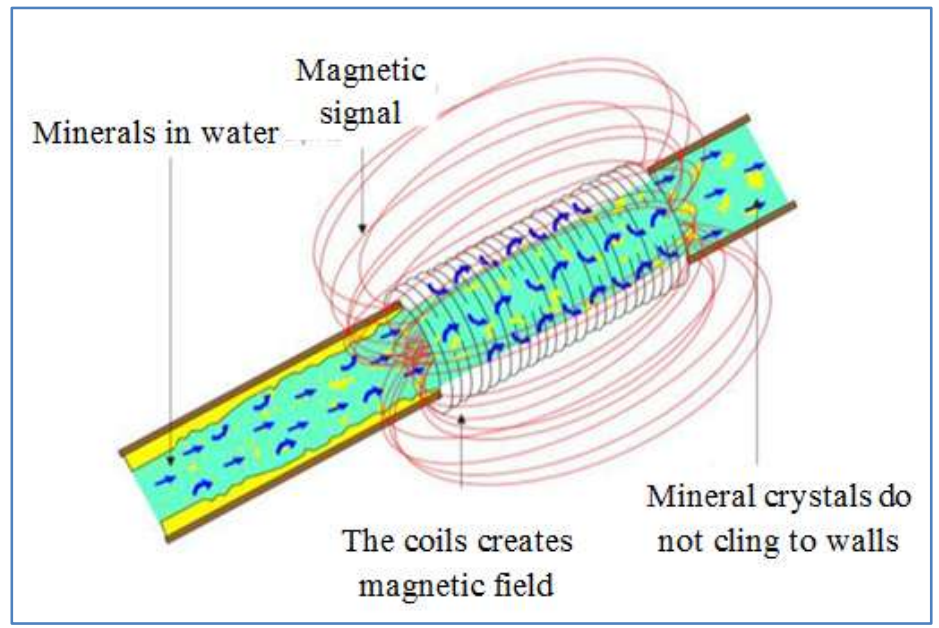

Fig-1: Principle of creating magnetic field

\section{Experimental model design}

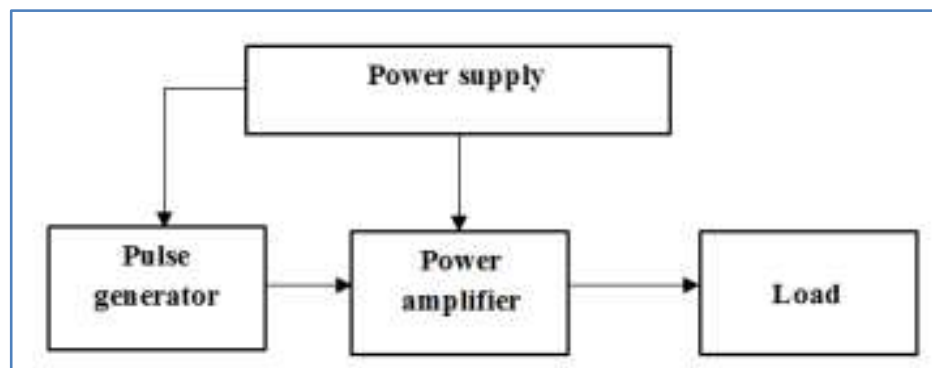

Fig-2: Block diagram of magnetic field generation system

The power supply is designed $\pm 35 \mathrm{~V}_{\mathrm{DC}}$ to provide power amplifier and $12 \mathrm{~V}_{\mathrm{DC}}$ to supply for pulse generator.

Pulse generator uses the Arduino due to generate square pulses with different frequencies.

The power amplifier is designed $350 \mathrm{~W}$ with a frequency response from $20 \mathrm{~Hz}$ to $20 \mathrm{KHz}$, the amplification factor is $35 \mathrm{~dB}$ and load is $4 \Omega$.

The magnetic field tube is used cylindrical tube with iron material, diameter $150 \mathrm{~mm}$, length 650 $\mathrm{mm}$, and thickness $3.5 \mathrm{~mm}$.
The coil generates a magnetic field using copper core wire with a diameter of $1.5 \mathrm{~mm}$, a length of $200 \mathrm{~m}$, and the total resistance $3.2 \Omega$.

\section{Experimental approach}

We use a tank with filled water; the dimensions of the tank are $850 \mathrm{~mm}$ in length, $450 \mathrm{~mm}$ for width and $600 \mathrm{~mm}$ in height. The TDS concentration in water was measured as $1182 \mathrm{ppm}$ and $\mathrm{PH}$ concentration in water was measured as 11.2. The magnetic field tube as Figure 3 is placed inside the water tank. We also adjusted the average voltage on coils to generate magnetic fields of $50 \mathrm{~V}$ at all frequencies. After every hour, we measure the concentration of TDS and PH water. The measurement results are presented in experimental section.

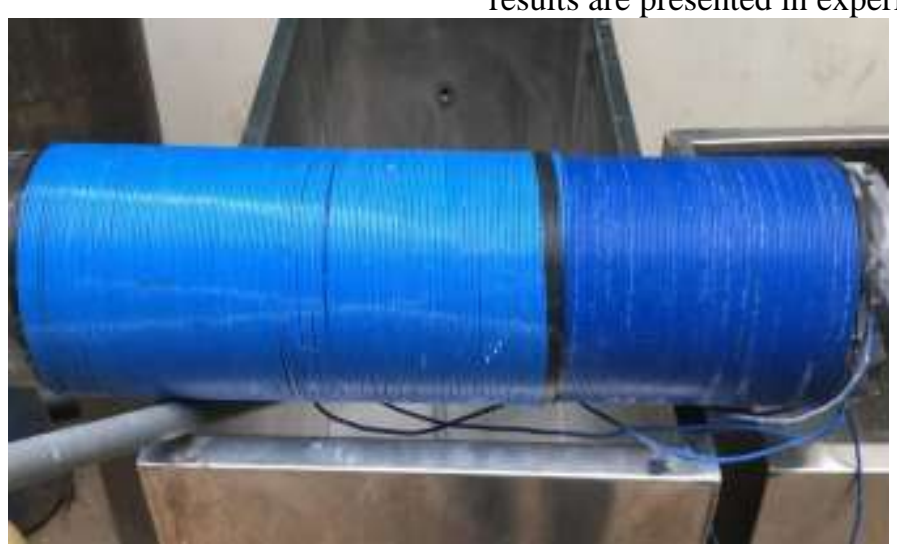

Fig-3: Magnetic field devices 


\section{EXPERIMENTAL RESULTS}

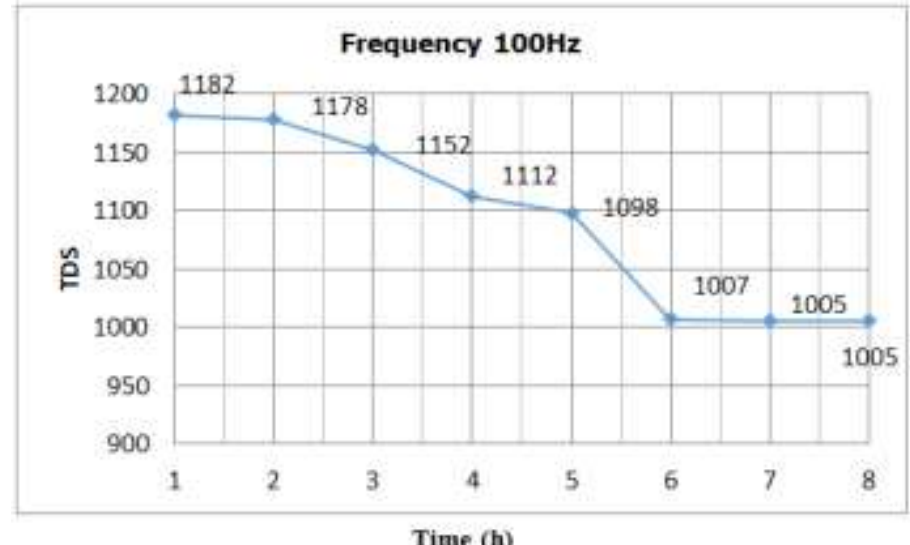

Fig-4: TDS concentration measurement results at frequency $100 \mathrm{~Hz}$

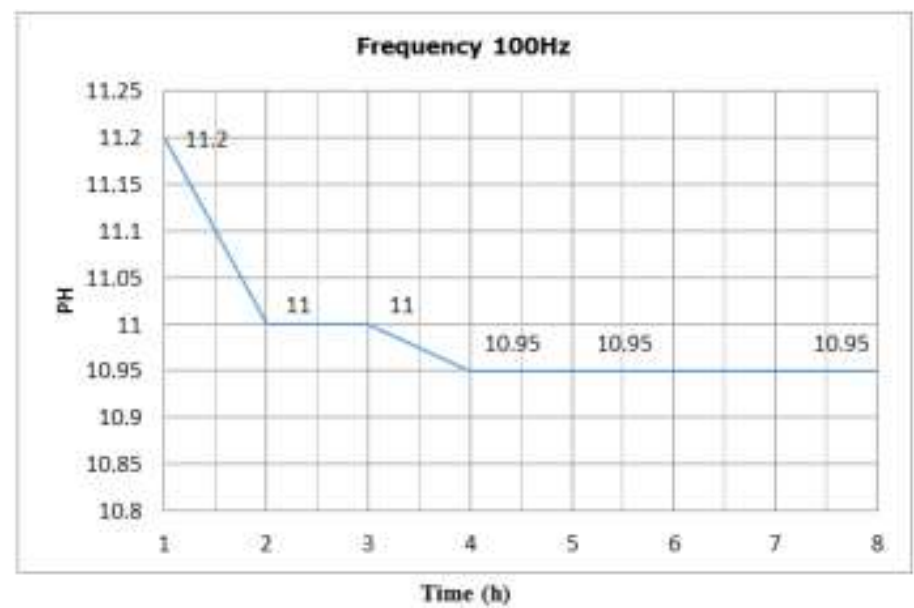

Fig-5: PH concentration measurement results at frequency $100 \mathrm{~Hz}$

Figure 4 and Figure 5 show measurable results of TDS and PH concentration at frequency $100 \mathrm{~Hz}$. From Figure 4 and Figure 5, we observe that the method in this research can offer improved performance power water.

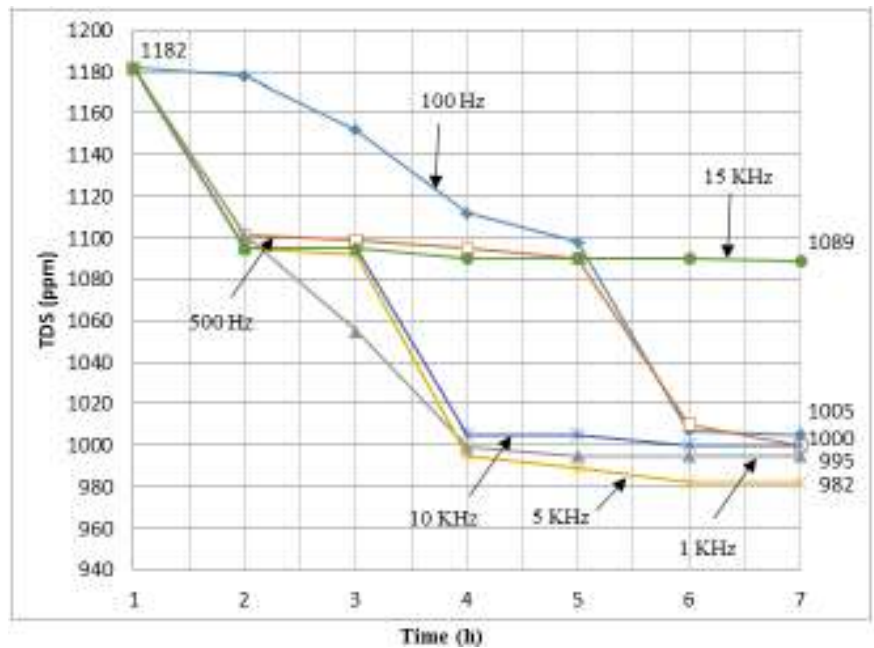

Fig-6: TDS concentration measurement results at frequency $100 \mathrm{~Hz}, 500 \mathrm{~Hz}, 1 \mathrm{KHz}, 5 \mathrm{KHz}, 10 \mathrm{KHz}$ and $15 \mathrm{KHz}$ 


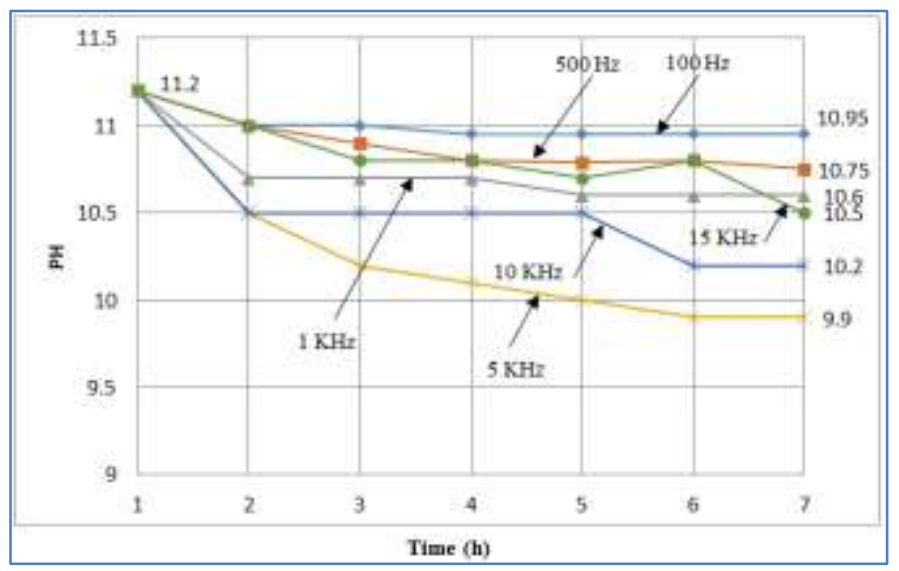

Fig-7: PH concentration measurement results at $100 \mathrm{~Hz}, 500 \mathrm{~Hz}, 1 \mathrm{KHz}, 5 \mathrm{KHz}, 10 \mathrm{KHz}$ and $15 \mathrm{KHz}$

Figure 6 displays the result of TDS concentration measurement frequency $100 \mathrm{~Hz}, 500 \mathrm{~Hz}$, $1 \mathrm{KHz}, 5 \mathrm{KHz}, 10 \mathrm{KHz}$, and $15 \mathrm{KHz}$. Figure 6 illustrates that the magnetic field of frequency $5 \mathrm{KHz}$ for best processing efficiency and the magnetic field at $5 \mathrm{KHz}$ frequency is not good effective.

Figure 7 displays the result of $\mathrm{PH}$ concentration measurement frequency $100 \mathrm{~Hz}, 500 \mathrm{~Hz}$, $1 \mathrm{KHz}, 5 \mathrm{KHz}, 10 \mathrm{KHz}$, and $15 \mathrm{KHz}$. Moreover, Figure 7 also illustrates that the magnetic field of frequency $5 \mathrm{KHz}$ for best processing efficiency and the magnetic field at $5 \mathrm{KHz}$ frequency is not good effective.

From Figure 6 and Figure 7, we observe that the magnetic field at $5 \mathrm{KHz}$ gives the best effective both in TDS concentration and PH concentrations.

\section{CONCLUSION}

This research presented as a result of treatment method of water based on the magnetic devices. The major contribution of this research was designed a magnetic generating system to reduce TDS and PH concentrations in water, which could be applied in boilers. Experimental results showed that concentration of PH and TDS in water was satisfactory to supply for boilers according to Vietnamese standards.

\section{ACKNOWLEDGEMENT}

We would like to thank the Ho Chi Minh City University of Food Industry (HUFI) for their funding under the Contract No. 87/HD-DCT.

\section{REFERENCES}

1. Alimi, F., Tlili, M. M., Amor, M. B., Maurin, G., \& Gabrielli, C. (2009). Effect of magnetic water treatment on calcium carbonate precipitation: Influence of the pipe material. Chemical Engineering and Processing: Process
Intensification, 48(8), 1327-1332.

2. Alimi, F., Boubakri, A., Tlili, M. M., \& Ben Amor, M. (2014). A comprehensive factorial design study of variables affecting $\mathrm{CaCO} 3$ scaling under magnetic water treatment. Water science and technology, 70(8), 1355-1362.

3. Chang, M. C., \& Tai, C. Y. (2010). Effect of the magnetic field on the growth rate of aragonite and the precipitation of $\mathrm{CaCO} 3$. Chemical Engineering Journal, 164(1), 1-9.

4. Lee, S. H., \& Cho, Y. I. (2002). Velocity effect on electronic-antifouling technology to mitigate mineral fouling in enhanced-tube heat exchanger. International Journal of Heat and Mass Transfer, 45(20), 4163-4174.

5. Xiaokai, X. (2008). Research on the electromagnetic anti-fouling technology for heat transfer enhancement. Applied Thermal Engineering, 28(8-9), 889-894.

6. Tijing, L. D., Kim, H. Y., Lee, D. H., Kim, C. S., \& Cho, Y. I. (2010). Physical water treatment using RF electric fields for the mitigation of $\mathrm{CaCO} 3$ fouling in cooling water. International Journal of Heat and Mass Transfer, 53(7-8), 1426-1437.

7. Al Nasser, W. N., Pitt, K., Hounslow, M. J., \& Salman, A. D. (2013). Monitoring of aggregation and scaling of calcium carbonate in the presence of ultrasound irradiation using focused beam reflectance technology, 238, 151-160.

8. Baker, J. S., \& Judd, S. J. (1996). Magnetic amelioration of scale formation. Water Research, 30(2), 247-260.

9. Tai, C. Y., Chang, M. C., Liu, C. C., \& Wang, S. S. S. (2014). Growth of calcite seeds in a magnetized environment. Journal of crystal growth, 389, 5-11. 